Old Dominion University

ODU Digital Commons

$10-2018$

\title{
Electrostatic Design and Conditioning of a Triple Point Junction Shield for a -200 kV DC High Voltage Photogun
}

\author{
G. Palacios-Serrano \\ Old Dominion University, gpala001@odu.edu \\ F. Hannon \\ C. Hernandez-Garcia \\ M. Poelker \\ H. Baumgart \\ Old Dominion University, hbaumgar@odu.edu
}

Follow this and additional works at: https://digitalcommons.odu.edu/ece_fac_pubs

Part of the Electrical and Computer Engineering Commons, and the Nuclear Commons

\section{Original Publication Citation}

Palacios-Serrano, G., Hannon, F., Hernandez-Garcia, C., Poelker, M., \& Baumgart, H. (2018). Electrostatic design and conditioning of a triple point junction shield for a $-200 \mathrm{kV} \mathrm{DC}$ high voltage photogun. Review of Scientific Instruments, 89, 104703. doi:10.1063/1.5048700

This Article is brought to you for free and open access by the Electrical \& Computer Engineering at ODU Digital Commons. It has been accepted for inclusion in Electrical \& Computer Engineering Faculty Publications by an authorized administrator of ODU Digital Commons. For more information, please contact digitalcommons@odu.edu. 


\title{
Electrostatic design and conditioning of a triple point junction shield for a $-\mathbf{2 0 0} \mathrm{kV}$ DC high voltage photogun
}

\author{
G. Palacios-Serrano, ${ }^{1,2}$ F. Hannon, ${ }^{2}$ C. Hernandez-Garcia, ${ }^{2}$ M. Poelker, ${ }^{2}$ and H. Baumgart ${ }^{2}$ \\ ${ }^{1}$ Department of Electrical Engineering, Old Dominion University, Norfolk, Virginia 23529, USA \\ ${ }^{2}$ Thomas Jefferson National Accelerator Facility, Newport News, Virginia 23606, USA
}

(Received 17 July 2018; accepted 17 September 2018; published online 3 October 2018)

\begin{abstract}
Nuclear physics experiments performed at the Continuous Electron Beam Accelerator Facility (CEBAF) at the Jefferson Lab require a DC high voltage photogun to generate polarized electron beams from GaAs photocathodes. The photogun uses a tapered ceramic insulator that extends into the vacuum chamber and mechanically holds the cathode electrode. Increasing the operating voltage from nominal $-130 \mathrm{kV}$ to $-200 \mathrm{kV}$ will provide lower beam emittance, better transmission through injector apertures, and improved photocathode lifetime. This desire to increase the photogun operating voltage led to the design of a triple-point-junction shield electrode which minimizes the electric field at the delicate insulator-metal-vacuum interface and linearizes the potential across the insulator, thus reducing the risk of arcing along the ceramic insulator. This work describes the results obtained using COMSOL ${ }^{\circledR}$ electrostatic-field simulation software and presents the high voltage conditioning results of the upgraded $-200 \mathrm{kV}$ CEBAF photogun. Published by AIP Publishing. https://doi.org/10.1063/1.5048700
\end{abstract}

\section{INTRODUCTION}

The nuclear physics experiments performed at the Jefferson Lab $12 \mathrm{GeV}$ Continuous Electron Beam Accelerator Facility (CEBAF) require a DC high voltage photo-electron gun with a GaAs photocathode to generate spin-polarized electron beams. Over a period of years, the photoguns employed at CEBAF have undergone numerous design changes. ${ }^{1}$ Today's CEBAF photogun relies on an inverted insulator design, ${ }^{2}$ based on a compact tapered ceramic insulator that extends into the vacuum chamber which mechanically holds the metallic cathode electrode. Compared to other photoguns that use large cylindrical insulators, this design significantly reduces the amount of metal biased at high voltage, which reduces the likelihood of field emission. Reducing field emission is a requirement for reliable photogun operation, since field emission stimulates gas desorption which degrades the vacuum quality inside the chamber which in turn degrades the photocathode quantum efficiency $(\mathrm{QE})$ lifetime through ion bombardment. ${ }^{3}$

Presently, the CEBAF inverted-insulator photogun operates at a bias voltage of $-130 \mathrm{kV}$. Increasing the operating voltage to $-200 \mathrm{kV}$ will provide lower beam emittance, better transmission through injector apertures, and improved photocathode lifetime because the residual gas ionization cross section decreases with electron beam kinetic energy. ${ }^{4}$

Although the present CEBAF photogun has been successfully operated at $-200 \mathrm{kV}, 5$ concerns that long term operation at this voltage would ultimately lead to high voltage breakdown prompted the redesign of the cathode electrode, including the addition of a triple-point-junction shield electrode. COMSOL ${ }^{\circledR}$ - a multiphysics software package—was used to simulate the new higher voltage photogun. COMSOL can interpret imported computer aided design (CAD) files that describe complicated three dimensional (3D) non-symmetric shapes. It can also distinguish materials with different electrical conductivity and dielectric constants. ${ }^{6}$ Moreover, the highresolution 3D electrostatic field maps of the cathode-anode gap that COMSOL provides could improve the accuracy of particle tracking code simulations that rely on this information. These factors motivated the implementation of the following improvements to the new, higher voltage photogun:

(a) Modify the cathode electrode shape by adding a "screening electrode" or "shield," which serves to minimize the electric field at the insulator-metal-vacuum interface, known as the triple-point-junction. This shield also serves to linearize the potential across the insulator. These characteristics minimize the risk of arcing along the high voltage cable termination. ${ }^{7}$

(b) Replace the existing undoped alumina ceramic insulator with a customized doped alumina insulator to provide some degree of conductivity for charge drainage. ${ }^{8}$

This work describes an improved $-200 \mathrm{kV}$ DC high voltage photogun designed using COMSOL electrostatic field simulation software, together with high voltage conditioning results.

\section{CEBAF PHOTOGUN DESIGNS}

Three-dimensional CAD models were generated for both photoguns: the existing CEBAF photogun that normally operated at $-130 \mathrm{kV}$ and employing a tee-shaped cathode electrode without a triple-point-junction shield, and a new photogun with a triple-point-junction shield intended to permit reliable operation at $-200 \mathrm{kV}$. The 3D CAD models were obtained using SolidWorks ${ }^{\circledR}$. Highly detailed modeling was performed at the high voltage side of the insulator and at the ground flange where Kovar ${ }^{\mathrm{TM}}$ ring braze joints provide the metal/insulator 

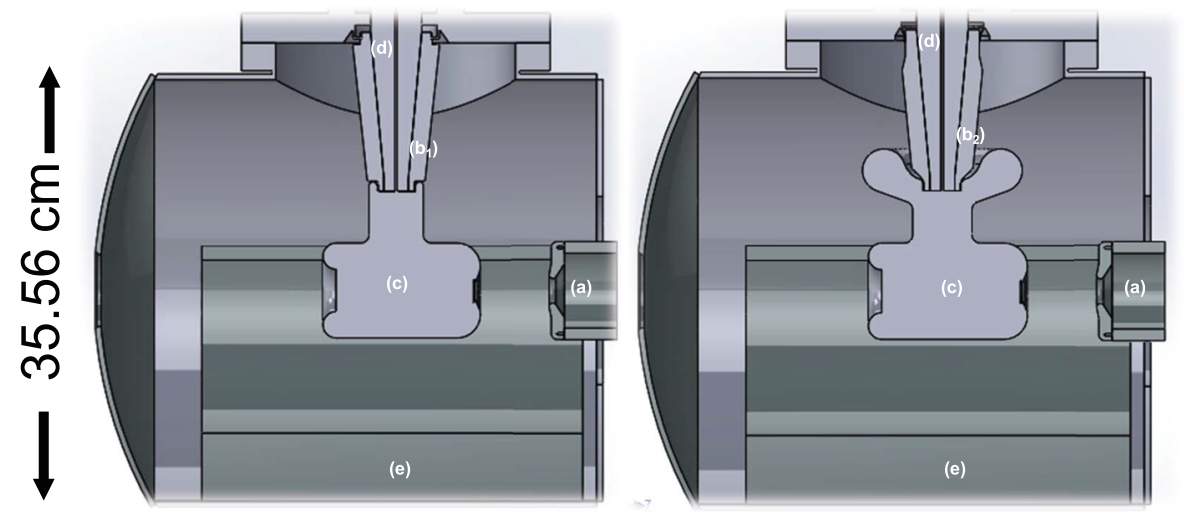

FIG. 1. (Left) Current CEBAF photogun with an un-doped ceramic insulator and (right) an updated photogun with a doped ceramic insulator and a triplepoint-junction shield. Vacuum chamber with (a) the anode structure and $\left[\left(b_{1}\right)\right.$ and $\left.\left(b_{2}\right)\right]$ tapered ceramic insulators with (c) the cathode electrode attached. $\mathrm{HV}$ conductor surrounded with (d) vulcanized rubber and (e) grounded nonevaporable getter vacuum pumps.

interface. Additionally the conductivity and permittivity of the different materials were accounted for using the COMSOL AC/DC electric currents interface, ${ }^{9}$ a feature not available in previously used free-distribution simulation software Poisson. ${ }^{10}$ Another useful feature of COMSOL was the possibility of defining different mesh sizes for individual parts of the model, which saves computational time and might help improve the resolution of the electrostatic field map of the cathode/anode gap used with electron beam/particle tracking software to predict photogun operational performance when generating beams.

Both photogun designs employ the same vacuum chamber housing (see Fig. 1). The cylindrical stainless steel vacuum chamber ( $35.6 \mathrm{~cm}$ diameter) has a flat front plate that accommodates the anode structure and a dish-head back plate. The top ConFlat ${ }^{\circledR}$ flange ( $25.4 \mathrm{~cm}$ diameter) supports the insulator and cathode electrode. The hollow interior of the ceramic insulator is tapered to accommodate a commercial high voltage connector commonly known as R28 in the X-ray high voltage industry, consisting of an inner conductor surrounded by vulcanized rubber. Photocathodes attached to molybdenum pucks are held in place within the cathode electrode using sapphire rollers attached to leaf springs, which press the photocathode surface against a Pierce focusing electrode $\left(25^{\circ}\right)$. Photocathode pucks can be removed and inserted using a magnetic sample manipulator not shown in Fig. 1. There are Kovar rings brazed to each side of the insulator. At the ground side, the Kovar ring is welded to the $25.4 \mathrm{~cm}$ ConFlat flange. At the high voltage side, the Kovar collar is brazed to a short molybdenum cylinder, to which the cathode electrode is bolted.

The photogun has an array of non-evaporable getter (NEG) pumps (SAES WP-1250-ST707) that line the bottom of the vacuum chamber. The entire inner surface of the vacuum chamber was coated with an in-house manufactured NEG film. Together, the NEG pumps, the NEG coating, and a small diodeion pump provide sufficient pumping to achieve vacuum levels below $2 \times 10^{-12}$ Torr $\left(\mathrm{N}_{2}\right.$ equivalent). ${ }^{11}$ A grounded wire mesh (not shown in the simulation) placed atop the NEG pumps defines the ground plane and helps preventing the charging of particulate matter that NEG pumps often produce.

The lower voltage $-130 \mathrm{kV}$ CEBAF photogun employs an un-doped insulator composed of $97.7 \%$ alumina. It is $12.9 \mathrm{~cm}$ long with an outer diameter tapering from 6.9 to
$4.9 \mathrm{~cm}$. The insulator for the higher voltage $-200 \mathrm{kV}$ photogun has slightly different dimensions at the Kovar braze joints, in part to accommodate the addition of the electrostatic triplepoint-junction shield. This insulator is $94.4 \%$ alumina doped with a vendor-proprietary substance that serves to reduce the insulator bulk resistivity, to drain away the accumulated charge that might accrue on the insulator, for example, as a result of field emission or ion bombardment. ${ }^{12}$

\section{TRIPLE-POINT-JUNCTION SHIELD DESIGN CRITERIA}

The electric currents interface AC/DC module of COMSOL takes into account the electrical conductivity and permittivity of all components for the electrostatics calculations. ${ }^{9}$ Simulations of both photogun configurations were performed using $-200 \mathrm{kV}$ bias voltage applied to the cathode. Other key parameters used in the simulations for each assembly were as follows:

i. A high voltage cable inserted into the ceramic insulator, with the vulcanized rubber plug $\left(\varepsilon_{\mathrm{r}}=2.3\right)$ located between the center high voltage conductor and the insulator inner wall in both photogun designs.

ii. An un-doped ceramic insulator, $97.7 \%$ alumina employed on the updated photogun, dielectric constant $\varepsilon_{\mathrm{r}}=9.1$, and conductivity $\sigma=2 \times 10^{-14} \mathrm{~S} / \mathrm{m}$.

iii. A doped ceramic insulator, $94.4 \%$ alumina employed on the updated photogun, dielectric constant $\varepsilon_{\mathrm{r}}=8.4$, and conductivity $\sigma=2 \times 10^{-12} \mathrm{~S} / \mathrm{m}$.

iv. The NEG pump array, anode, upper flange, and vacuum chamber were designated as grounded metal.

As described below, the electrostatic simulations of the present $-130 \mathrm{kV}$ CEBAF photogun biased at $-200 \mathrm{kV}$ indicated very high field strength values near the triplepoint-junction $(\sim 15 \mathrm{MV} / \mathrm{m})$, increasing the risk of insulator breakdown or flashover. It is widely believed that flashover originates at the triple-point-junction ${ }^{7}$ so reducing the field strength at this location is a sensible goal. The transverse component of the electric field near the triple-point-junction is especially important due to its tendency to drag charged particles towards the insulator surface, inducing secondary electron emission avalanche and/or electron cascades within a thin layer near the surface, that in turn might desorb gas that once ionized 
can lead to breakdown along the insulator surface. Furthermore, charge accumulation on the insulator surface can lead to breakdown by changing the electric field distribution near the insulator surface. ${ }^{8}$ In addition, when properly designed, the triple-point-junction shield can linearize the potential gradient across the insulator length. ${ }^{12}$

The outer radius of the triple-point-junction shield was specified not to extend beyond the horizontal length of the teeshaped electrode, to minimize the impact on the electric field within the cathode-anode gap that affects an electron beam trajectory. The vertical height of the shield along the length of the insulator was kept short to maintain sufficient distance to the top ground flange, to keep the field strength low at the "cusp" of the shield. The interior perimeter of the shield was tapered away from the insulator, diminishing the field on its inner surface. Overall, the contour of the shield was designed to keep the maximum value of the field around the cusp below $10 \mathrm{MV} / \mathrm{m}$ at $-200 \mathrm{kV}$, to prevent field emission and minimize the amount of cathode electrode material added to the vacuum chamber, which represents an additional gas load.

\section{ELECTROSTATIC DESIGN RESULTS}

Simulation results are presented in Fig. 2 which provides lateral cross section views of both photogun designs, with false-color graphics used to indicate areas of high
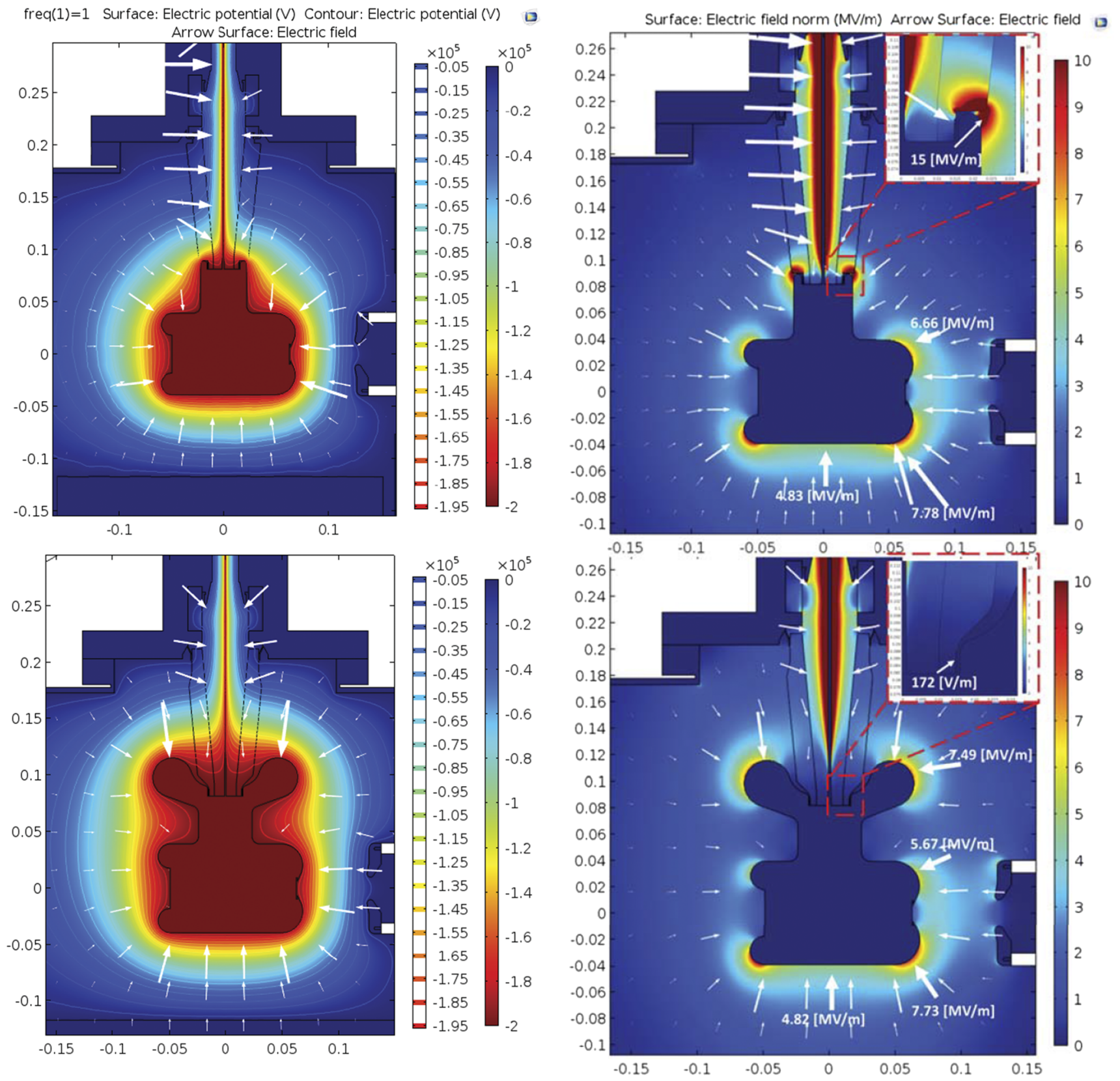

FIG. 2. False-color lateral cross section views of the electrostatic field strength within two photoguns: (top) the present day CEBAF photogun with un-doped alumina insulator and (bottom) the new photogun that includes a triple-point-junction shield electrode and doped alumina insulator. Potential (left) and electric field maps (right) are for both photoguns biased at $-200 \mathrm{kV}$. The white arrows are proportional to the electric field normal to the equipotential lines. Horizontal axis scale in meters. The color scale corresponds to the potential in V (left) and electric field norm in MV/m (right). 
potential (left) and field strength (right). The high field strength values within the rubber plug region do not pose a design concern due to the high dielectric constant of this material. The simulations show a field strength reduction of $\sim 100 \%$ near the triple-point-junction: only $172 \mathrm{~V} / \mathrm{m}$ in the new photogun design, compared to $15 \mathrm{MV} / \mathrm{m}$. The highest field strength in the new photogun design is $\sim 7.5 \mathrm{MV} / \mathrm{m}$, at the "cusp" of the trip-point-junction shield, a value deemed acceptable. Other locations of interest are shown in Fig. 2, as these points represent the key positions in the photogun where high electric fields might lead to detrimental field emission, arcing, or unwanted modifications of the electric field within the cathode-anode gap that could negatively impact beam delivery. The field strength at these locations in the new photogun is comparable or less than values at similar locations within the older gun design.

Figure 3 (top) shows the electric field strength (potential gradient) and (bottom) the electric potential plotted along the length of the insulator at the rubber plug-insulator interface, for both photogun designs. The authors suggest that the best electrostatic design provides a relatively small electric field strength near the triple-point-junction and a potential that varies linearly along the length of the insulator. As shown in Fig. 3, the new electrostatic design (red) provides considerable improvement over the old design (blue). The electric field strength in the new photogun is very small near the triplepoint-junction $(0.08<\mathrm{y}<0.1)$ and gradually increases to $\sim 4 \mathrm{MV} / \mathrm{m}$, representing a $\sim 22 \%$ reduction overall, compared to the old photogun design. Similarly, the potential along the length of the insulator varies more linearly.

\section{CATHODE-ANODE GAP}

Another key aspect of the photogun electrostatic design is the magnitude of the transverse electric field component along the center line between the photocathode and the anode. Ideally, the transverse electric field in this region should be zero. Photoguns with symmetric cathode/anode designs ${ }^{13}$ satisfy this condition. The "side-insulator" design described here provides an important practical advantage related to photocathode installation within the cathode electrode, but it introduces an asymmetry in the electrostatic field within the cathodeanode gap. The simulations described above indicate that the electrode triple-point-junction shield amplifies this field asymmetry: Fig. 4 shows a $60 \%$ increase in the transverse component of the electric field at the approximate midpoint of the cathode-anode gap due to the presence to the triple-pointjunction shield. To better appreciate the possible impact of this enhanced transverse electric field on electron beam quality, particle tracking code simulations will be performed and

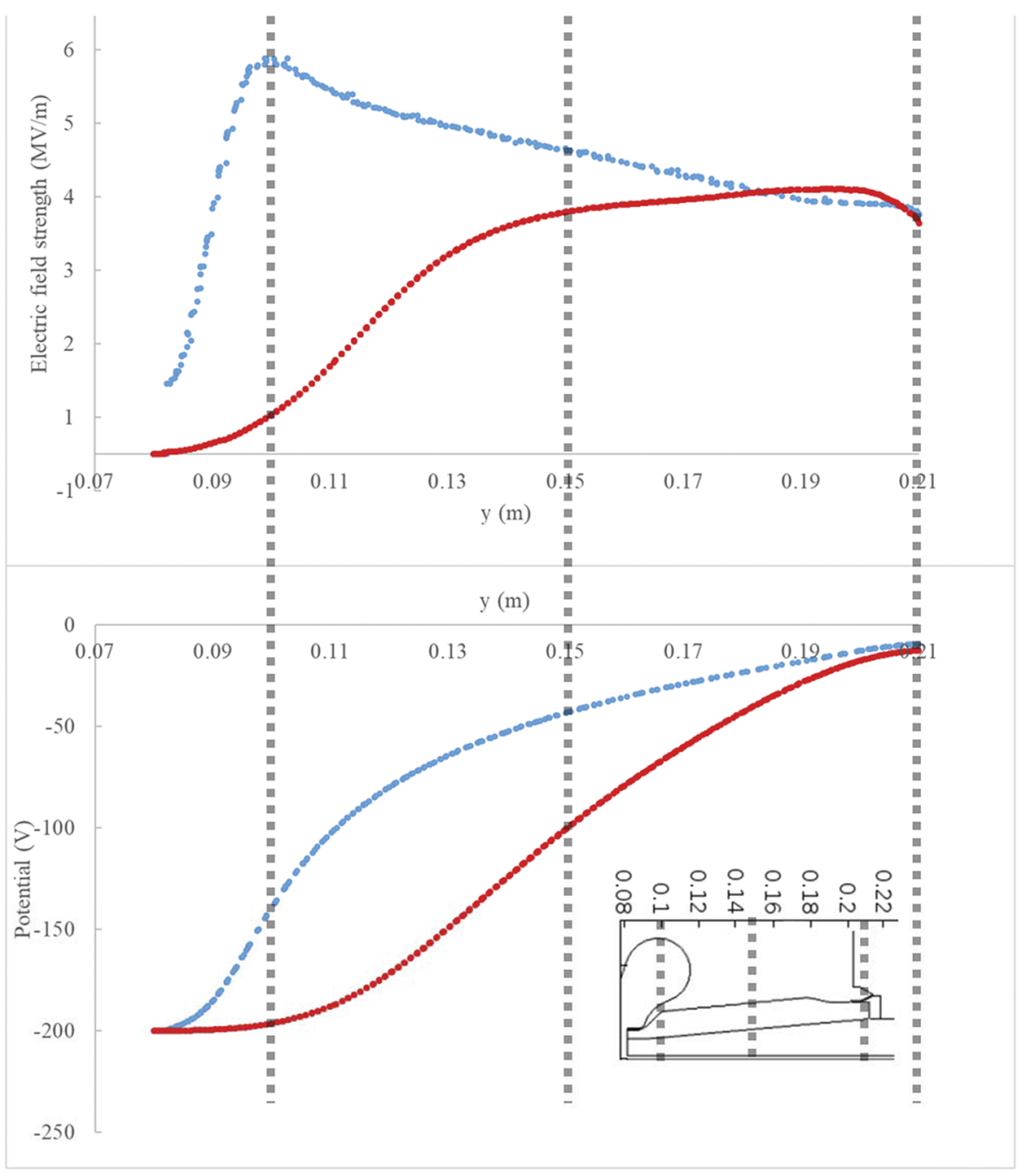

FIG. 3. (Top) Electric field strength and (bottom) the potential along the rubber plug-ceramic insulator interface for two photoguns: (blue) the present day CEBAF photogun with un-doped alumina insulator and (red) the new photogun that includes a triple-point-junction shield electrode and a doped alumina insulator. Both photoguns biased at $-200 \mathrm{kV}$. The dotted gray lines represent the positions along the insulator (see the inset). 


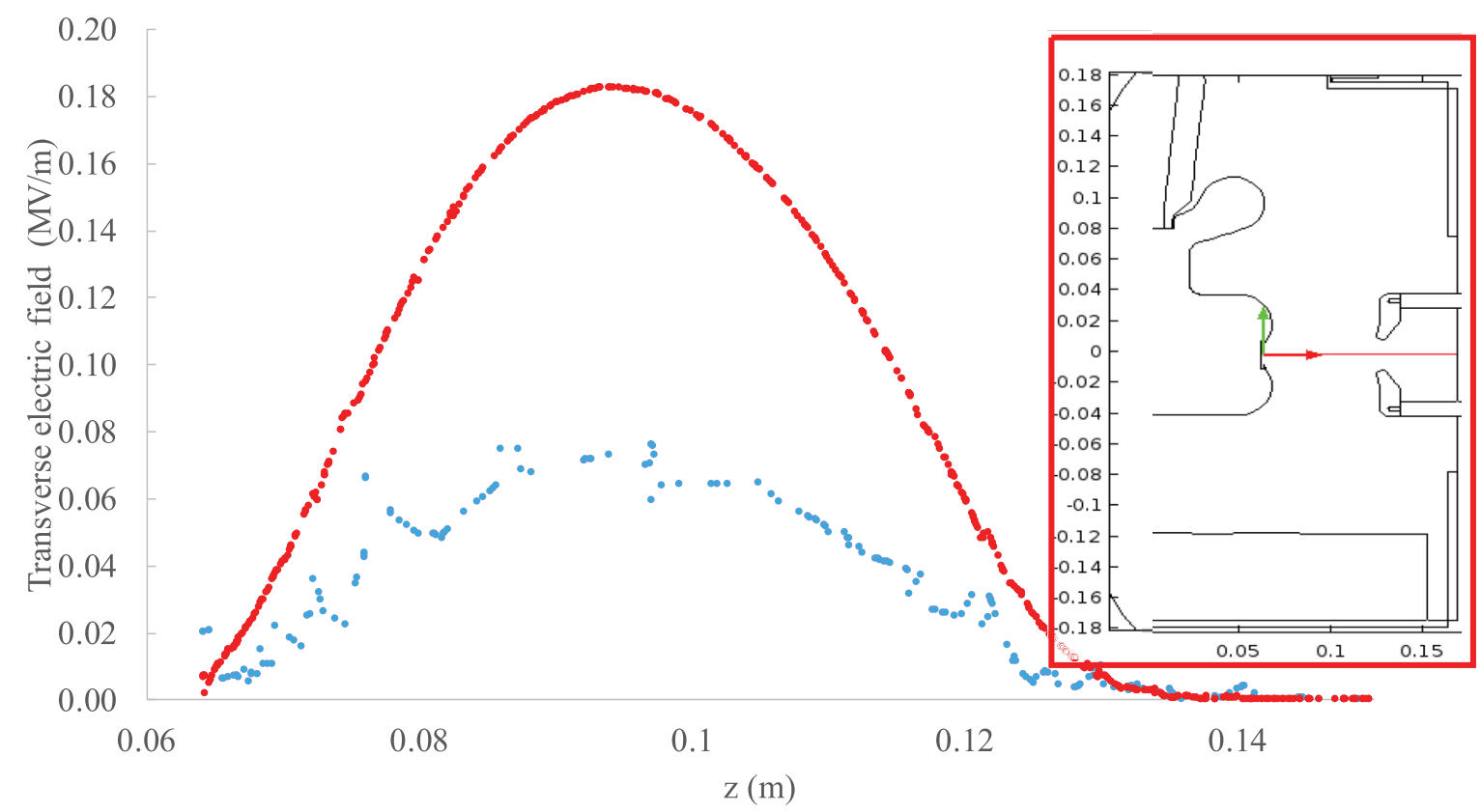

FIG. 4. Transverse electric field within the cathode-anode gap, along the centerline of the photogun as shown by the red line in the inset detail. Blue/red data points correspond to old/new photogun designs, with $-200 \mathrm{kV}$ bias voltage.

compared to the beam-based evaluation of photogun performance at CEBAF.

In the course of recent efforts to operate Jefferson Lab photoguns at higher bias voltage, it has become apparent that the inverted-insulator photogun high voltage design must consider three important parameters: electrode design to minimize field emission, electrode design to minimize catastrophic high voltage breakdown, and electrode design to preserve photocathode intrinsic emittance. This paper addressed only two of these priorities. A future publication describing the operational performance of the CEBAF $200 \mathrm{kV}$ dc high voltage photogun will address all of the inter-related high voltage design considerations.

\section{HIGH VOLTAGE GAS CONDITIONING}

Before a DC high voltage photogun can be put into service, the cathode electrode must be "conditioned" to eliminate field emission sites caused by micro-protrusions or surface contamination. The cathode electrode was polished to obtain a mirror-like surface and carefully cleaned before installation, but field emission sites are nearly always present during the first application of voltage. At the Jefferson Lab and elsewhere, it is customary to perform high voltage conditioning of the electrode in the presence of an inert gas within the vacuum chamber, ${ }^{14}$ where field emitters are eliminated via sputtering and ion implantation. Figure 5 shows the high voltage conditioning history of the cathode electrode with a triplepoint-junction shield, where a field emitter was processed after approximately $2 \mathrm{~h}$ of conditioning at voltage up to $-228 \mathrm{kV}$. Field emission was monitored using Geiger-Müller x-ray monitors placed around the photogun. The photogun was allowed to "soak" at $-228 \mathrm{kV}$ for approximately $100 \mathrm{~h}$. The absence of field emitters during the soaking process was indicative of successful conditioning. After gas conditioning, the krypton was pumped away and voltage re-applied under

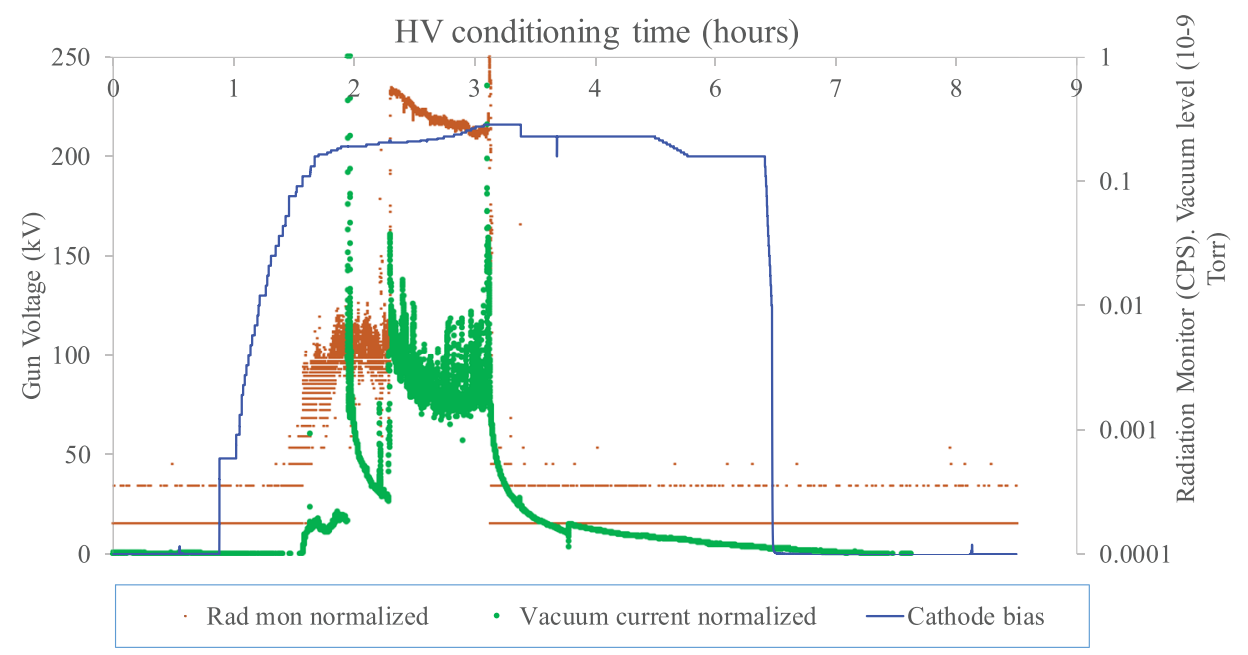

FIG. 5. High voltage conditioning history of the new cathode electrode with a triple-point-junction shield electrode: bias voltage (blue), vacuum level normalized to $1 \times 10^{-9}$ Torr (brown), and the signal from one of the GeigerMüller x-ray monitors near the photogun (green). 
ultrahigh vacuum conditions, with no field emission observed at the design operating voltage of $-200 \mathrm{kV}$.

\section{DISCUSSION AND FUTURE WORK}

COMSOL was used to simulate the electrostatic field conditions inside two dc high voltage photoguns and, in particular, to design a new cathode electrode with a triple-point-junction shield for a photogun intended to operate at $-200 \mathrm{kV}$. The new cathode electrode design significantly reduced the electric field strength at the triple-point-junction, and field strength values at other locations within the photogun were comparable to or lower than the values of the previous design. Besides protecting the triple-point-junction, the shield also serves to linearize the potential across the length of the insulator. This new cathode electrode design should greatly improve photogun reliability at the design operating voltage $-200 \mathrm{kV}$. These simulations are deemed more accurate than past simulations performed at the Jefferson Lab because COMSOL could account for material conductivity, permittivity, and complicated 3D shapes.

Regardless of the inherent limitations in the use of proprietary software, COMSOL could aid in the ability to predict photogun performance, through obtaining field maps in the region where the electron beam is produced, thus allowing the prediction of beam emittance. Additionally the implementation of multiphysics modeling to address the challenges of interacting electric and magnetic fields for future projects, namely, generation of magnetized electron beam for the proposed Electron Ion Collider JLEIC (see, for example, Ref. 15), design of a Wien-filter to orient the spin direction of $200 \mathrm{keV}$ polarized electron beams, and the possibility of simulating charge accumulation on surfaces to understand insulator failure and even particle beam tracking.

\section{ACKNOWLEDGMENTS}

This article was authored by Jefferson Science Associates, LLC, under U.S. DOE Contract No. DE-AC05-06OR23177. The U.S. Government retains a non-exclusive, paid-up, irrevocable, world-wide license to publish or reproduce this manuscript for U.S. Government purposes. The authors wish to thank J. Hansknecht, D. Machie, and K. Harding for assistance with CAD files.
${ }^{1}$ C. K. Sinclair, P. A. Adderley, B. M. Dunham, J. C. Hansknecht, P. Hartmann, M. Poelker, J. S. Price, P. M. Rutt, W. J. Schneider, and M. Steigerwald, "Development of a high average current polarized electron source with long cathode operational lifetime," Phys. Rev. Spec. Top.-Accel. Beams 10, 023501 (2007).

${ }^{2}$ P. A. Adderley, J. Clark, J. Grames, J. Hansknecht, K. Surles-Law, D. Machie, M. Poelker, M. L. Stutzman, and R. Suleiman, "Load-locked dc high voltage GaAs photogun with an inverted-geometry ceramic insulator," Phys. Rev. Spec. Top.-Accel. Beams 13, 010101 (2010).

${ }^{3}$ K. Aulenbacher, Ch. Nachtigall, H. G. Andresen, J. Bermuth, Th. Dombo, P. Drescher, H. Euteneuer, H. Fischer, D. v. Harrach, P. Hartmann, J. Hoffmann, P. Jennewein, K. H. Kaiser, S. Köbis, H. J. Kreidel, J. Langbein, M. Petri, S. Plützer, E. Reichert, M. Schemies, H.-J. Schöpe, K.-H. Steffens, M. Steigerwald, H. Trautner, Th. Weis, "The MAMI source of polarized electrons," Nucl. Instrum. Methods Phys. Res., Sect. A 391, 498 (1997).

${ }^{4}$ J. Grames, R. Suleiman, P. A. Adderley, J. Clark, J. Hansknecht, D. Machie, M. Poelker, and M. L. Stutzman, "Charge and fluence lifetime measurements of a dc high voltage GaAs photogun at high average current," Phys. Rev. ST Accel. Beams 14, 043501 (2011).

${ }^{5}$ P. Adderley, J. Clark, J. Grames, J. Hansknecht, M. Poelker, M. Stutzman, R. Suleiman, K. Surles-Law, J. McCarter, and M. BastaniNejad, "CEBAF $200 \mathrm{kV}$ inverted electron gun," in Proceedings of the 2011 Particle Accelerator Conference (IEEE, New York, NY, USA, 2011), pp. 1501-1503.

${ }^{6}$ COMSOL Multiphysics ${ }^{\circledR}$ v. 5.1, COMSOL AB, Stockholm, Sweden, www.comsol.com.

${ }^{7}$ H. Miller, "Surface flashover of insulators," IEEE Trans. Electr. Insul. 24(5), 765 (1989).

${ }^{8} \mathrm{H}$. C. Miller, "The effect of doping on the voltage holdoff performance of alumina insulators in vacuum," IEEE Trans. Electr. Insul. 20(3), 505 (1985).

${ }^{9}$ AC/DC Module User's Guide, COMSOL Multiphysics ${ }^{\circledR}$ v. 5.1, COMSOL $\mathrm{AB}$, Stockholm, Sweden.

${ }^{10} \mathrm{~K}$. Halbach, Lawrence Livermore National Laboratory Technical Report No. UCRL-17436, 1967.

${ }^{11}$ M. L. Stutzman, P. A. Adderley, Md A. A. Mamun, and M. Poelker, "Nonevaporable getter coating chambers for extreme high vacuum," J. Vac. Sci. Technol., A 36, 031603 (2018).

${ }^{12}$ C. Hernandez-Garcia, M. Poelker, and J. Hansknecht, "High voltage studies of inverted-geometry ceramic insulators for a $350 \mathrm{kV}$ dc polarized electron gun,” IEEE Trans. Dielectr. Electr. Insul. 23(1), 418 (2016).

${ }^{13}$ J. Grames, P. Adderley, J. Brittian, J. L. Clark, J. C. Hansknecht, D. Machie, M. Poelker, M. Stutzman, R. B. Suleiman, and K. Surles-Law, "Lifetime measurements of high polarization strained-superlattice gallium arsenide at beam current $>1$ milliamp using a new $100 \mathrm{kV}$ load lock photogun," in Particle Accelerator Conference 2007 (IEEE, June 2007), pp. 3130-3132.

${ }^{14}$ M. BastaniNejad, A. A. Elmustafaa, E. Forman, J. Clark, S. Covert, J. Grames, J. Hansknecht, C. Hernandez-Garcia, M. Poelker, and R. Suleiman, "Improving the performance of stainless-steel DC high voltage photoelectron gun cathode electrodes via gas conditioning with helium or krypton," Nucl. Instrum. Methods Phys. Res., Sect. A 762, 135 (2014).

${ }^{15}$ F. Lin, Ya. S. Derbenev, V. S. Morozov, F. Pilat, G. H. Wei, Y. Zhang, Y. Cai, Y. M. Nosochkov, M. Sullivan, M.-H. Wang, "Simulations of nonlinear beam dynamics in the JLEIC electron collider ring," in Proceedings of NAPAC2016, Chicago, IL, USA, 2016, ISBN: 978-3-95450-1. 